\title{
The Link between Thyroid Function and Depression
}

\author{
Mirella P. Hage and Sami T. Azar \\ Division of Endocrinology and Metabolism, Department of Internal Medicine, American University of Beirut Medical Center, \\ P.O. Box 11-0236, Riad El Solh, Beirut 1107 2020, Lebanon
}

Correspondence should be addressed to Sami T. Azar, sazar@aub.edu.lb

Received 25 July 2011; Revised 26 September 2011; Accepted 26 September 2011

Academic Editor: Michael Bauer

Copyright ( $) 2012$ M. P. Hage and S. T. Azar. This is an open access article distributed under the Creative Commons Attribution License, which permits unrestricted use, distribution, and reproduction in any medium, provided the original work is properly cited.

\begin{abstract}
The relation between thyroid function and depression has long been recognized. Patients with thyroid disorders are more prone to develop depressive symptoms and conversely depression may be accompanied by various subtle thyroid abnormalities. Traditionally, the most commonly documented abnormalities are elevated T4 levels, low T3, elevated rT3, a blunted TSH response to TRH, positive antithyroid antibodies, and elevated CSF TRH concentrations. In addition, thyroid hormone supplements appear to accelerate and enhance the clinical response to antidepressant drugs. However, the mechanisms underlying the interaction between thyroid function and depression remain to be further clarified. Recently, advances in biochemical, genetic, and neuroimaging fields have provided new insights into the thyroid-depression relationship.
\end{abstract}

\section{Introduction}

The association between thyroid function and psychiatric disorders particularly mood disorders has long been recognized. Historically, this association has been described more than 200 years ago. Parry in 1825 reported an increased incidence of "nervous affectations" in thyroid disorders. Gull in 1873 showed the relation between myxedema and psychosis that was confirmed in 1888 by the Committee of the Clinical Society. Later, Asher in 1949 coined the term "myxedema madness" to describe the mental state of subjects with hypothyroidism [1].

Today, it is well recognized that disturbances in thyroid function may significantly affect mental status including emotion and cognition. Both excess and insufficient thyroid hormones can cause mood abnormalities including depression that is generally reversible with adequate thyroid treatment. On the other hand, depression can be accompanied by subtle thyroid dysfunction. Overt thyroid disease is rare in depression. One to $4 \%$ of patients with affective disorders are found to have overt hypothyroidism while subclinical hypothyroidism occurs in $4 \%$ to $40 \%$ of these patients [2]. Furthermore, thyroid hormones are reported by many authors to be an effective adjunct treatment for depression.
In this paper, we will present an overview of thyroid hormone metabolism in the brain, reexamine the different observations and clinical studies assessing the relationship between thyroid and depression, and shed light on the advances in neuroimaging approaches in this field. Understanding the link between both disorders will guide clinicians to appropriately interpret thyroid function tests in depression, better understand the pathophysiology of both diseases, and try to identify the subjects who will benefit the most from thyroid supplementation.

\section{Literature Search}

A PubMed search was performed through the English literature from 1969 to present using the keywords: "acceleration," "antidepressant treatments," "augmentation," "brain," "depression," "hyperthyroidism," "hypothyroidism," and "mood disorder."

\section{Overview of Thyroid Hormone Metabolism in the Brain}

The hypothalamic-pituitary-thyroid axis (HPT) is a complex interplay between several factors: thyroid hormones, deiodinase enzymes, transporter proteins, and receptors. An understanding of the interactions of these factors may contribute to 
better elucidate the pathophysiology of psychiatric disorders as well as the response to psychiatric treatment.

The secretion of thyroid hormones is regulated by pituitary thyrotropin (TSH) which itself is stimulated by hypothalamic thyrotropin-releasing hormone (TRH) and downregulated by serum thyroid hormones. Twenty percent of triiodothyronine (T3) in the cerebral cortex is secreted directly by the thyroid while $80 \%$ is derived from local conversion of thyroxine (T4) by deiodination [3, 4]. Most of the T4 enter the brain via a number of transporters including transthyretin (TTR), a thyroid hormone transport protein synthesized by the choroid plexus and secreted into the cerebrospinal fluid $[5,6]$. Deiodination occurs intracellularly mainly in glial cells and T4 must enter these cells through specialized plasma membrane carrier proteins including organic anion transporter polypeptide 1 (OATP1C1) and monocarboxylase transporter 8 (MCT8). The former preferentially transports $\mathrm{T} 4$ and $\mathrm{rT} 3$ while the latter is more specific for T3 transport [7]. In the glial cells, T4 is converted to T3 by the deiodinase enzyme type 2 (D2) while it is inactivated to $3,3^{\prime}, 5^{\prime}$-triiodothyronine (rT3) in the neuronal cells by the deiodinase enzyme type 3 (D3). The latter also deiodinates $\mathrm{T} 3$ into inactive T2. The actions of T3 are mediated by binding to thyroid hormone nuclear receptors (THRs). In the adult brain, THR- $\alpha$ is most highly expressed and constitutes 70-80\% of THR distribution [8].

Thus, the HPT axis includes complex pathways and impairment in its components has been linked in some studies to behavioral changes as will be further pointed out.

\section{Neuropsychiatric Manifestations of Thyroid Disorders}

Primary thyroid disorders including both hypothyroidism and hyperthyroidism may be accompanied by various neuropsychiatric manifestations ranging from mild depression and anxiety to overt psychosis.

Dysphoria, anxiety, irritability, emotional lability, and impairment in concentration constitute the classical neuropsychiatric symptoms occurring in hyperthyroidism or thyrotoxicosis. However, elderly patients may present in a state mimicking a depressive disorder with apathy, lethargy, and pseudodementia [9]. Anxiety disorders have been found to occur in approximately $60 \%$ of hyperthyroid patients while depressive disorders occurred in 31 to $69 \%$ [10,11].

On the other hand, hypothyroid patients frequently demonstrate features of depression, cognitive dysfunction, apathy, and psychomotor slowing. In severe forms of hypothyroidism, clinical symptoms may mimic that of melancholic depression and dementia [12]. However, there is less evidence on the association of subclinical hypothyroidism with cognitive dysfunction and affective disorders particularly depression although recently, a prevalence of $63.5 \%$ of depressive symptoms was reported in an Italian population with subclinical hypothyroidism. Nevertheless, therapy with levothyroxine alone was not sufficient to induce a total remission of depressive symptoms in this population [13]. Furthermore, Bauer et al. showed that TSH levels in hypothyroidism correlated with disease severity [14] and
Joffe and Levitt found a disparity in depressive symptoms manifestations and severity among patients with a low-normal TSH versus those with a high-normal TSH. However, in the latter study no difference in treatment outcome was observed between the two groups [15]. In patients treated with T4, psychological symptoms may persist even when they achieve a euthyroid state [16]. Impaired psychological wellbeing in these subjects may be related to the occurrence of genetic polymorphisms in the D2 gene [17] as well as the OATPC1 encoding gene [18].

According to the American Association of Clinical Endocrinologists, "The diagnosis of subclinical or clinical hypothyroidism must be considered in every patient with depression" [19]. Indeed, among the various neuropsychiatric manifestations of thyroid disorders, depression remains the most common [20].

\section{Thyroid Status in Patients with Depression}

Several thyroid abnormalities have been associated with mood disorders particularly depression. However, the vast majority of patients with depression do not have biochemical evidence of thyroid dysfunction $[21,22]$. When thyroid abnormalities exist, they consist mainly of elevated T4 levels, low T3, elevated rT3, blunted TSH response to TRH, positive antithyroid antibodies, and elevated cerebrospinal fluid (CSF) TRH concentrations. A state of brain hypothyroidism in the setting of systemic euthyroidism [23-25] has been suggested. This could result from a defect in the thyroid hormone receptor [26], or in the thyroid hormone transport and uptake into the brain and neuronal cells [7, 27]. Mice with receptor-mediated hypothyroidism caused by a heterozygous mutation in the THR $\alpha$ - 1 have shown increased depressive behavior responsive to continuous T3 administration [26]. Furthermore, lower levels of CSF TTR have been reported in patients with depression compared to controls [28-30] resulting in a state of "brain hypothyroidism" with, nonetheless, normal peripheral thyroid hormones [28]. Mutations in MCT8 have also been recognized to cause isolated brain hypothyroidism by blocking T3 transport into neurons $[8$, $31]$.

\section{Peripheral Thyroid Hormone Concentrations}

6.1. Thyroxine (T4). Studies examining total and free plasmatic T4 levels in patients with depression have shown inconsistent results. Serum T4 levels in the upper range of normal or slightly higher have been reported in depressed patients as compared to healthy or psychiatric controls. These levels have been found to regress after successful treatment of depression [32].

One mechanism explaining the increase in T4 seen in depression is the activation of hypothalamic TRH producing neurons and subsequent increase in thyroid function secondary to the rise in cortisol associated with depression [19, $24,33]$. In addition, it has been shown that elevated serum T4 levels fall after successful treatment of depression. A direct effect of antidepressants on the TRH neuron has been demonstrated resulting in an inhibition of TRH secretion [34]. 
This suggests that the decrease in T4 levels with initiation of antidepressants could be secondary to a direct effect on TRH neuron and thus to a reduced stimulation of the thyroid axis.

Recently, the Caerphilly Prospective Study examined the link between thyroid function and minor psychiatric morbidity among 2269 middle-aged men. A weak positive association between total T4 and chronic psychiatric morbidity was observed after 12.3 years of followup. However, this was consistent with chance after adjustments were done for social class, alcohol, and smoking behaviors. On the other hand, meta-analyses of seven studies showed TSH to be negatively correlated with depression and total $\mathrm{T} 4$ to be positively related to a depressed mood [35].

6.2. Triiodothyronine (T3) and 3,3', $5^{\prime}$-Triiodothyronine (rT3). In patients with depression and no other illnesses, a "low T3 syndrome" has been described [36]. In one study [37], a normal daily production of $\mathrm{T} 3$ was reported among unmedicated and moderately depressed patients. The combination of increased T4 yet normal T3 production supports the hypothesis of a reduced deiodination of T4 into T3 as seen in the euthyroid sick syndrome [37]. An elevated rT3 was also reported in association with unipolar depression [38] as demonstrated by Linnoila et al., and Kirkegaard and Faber found as well high rT3 levels in endogenous depression that normalized after electroconvulsive therapy [39]. It has been hypothesized that depression leads to inhibition of the D2 enzyme responsible for conversion of T4 into T3 due to the increase in cortisol levels [40]. This favors the production of rT3 by D3 enzyme. In addition, elevated levels of rT3 were found in CSF of patients with unipolar depression [41].

\section{Antithyroid Antibodies}

A prevalence of up to $20 \%$ of elevated titers of antithyroid antibodies has been documented in depressed patients in several reports compared to a $5-10 \%$ prevalence in the general population [42-45]. However, this should be viewed with caution since these reports either lacked a control group $[42,43,45]$ or showed no significant difference between the group with an affective disorder and the control group with a nonaffective psychiatric disorder [44]. Furthermore, whether this link may have any clinical significance remains unclear since it was most often accompanied by normal serum TSH concentrations $[42,43]$. In addition, Fountoulakis et al. found higher thyroid binding inhibitory immunoglobulins (TBII) in depressed patients suggesting the presence of an autoimmune process involving the thyroid gland in depressed patients [46].

\section{Blunted TSH Response and Abnormal Diurnal Rhythm}

Depression has been linked to various endogenous circadian rhythms abnormalities such as diurnal mood variation, abnormalities in core body temperature, cortisol secretion, and sleep-wake cycle [47]. In addition to these circadian dysfunctions, depression has been linked to an abnormal diurnal TSH rhythm as well. An absent TSH nocturnal surge [48] has been noted in depression and a lower basal TSH has been reported in major depression as opposed to nonmajor depression [49]. Furthermore, a blunted TSH response to TRH was reported in about $25-30 \%$ of depressed subjects compared to healthy ones [50-54]. One preeminent hypothesis to explain the above finding is that chronic TRH hypersecretion associated with depression leads to downregulation of pituitary TRH receptors $[24,53,55,56]$. In support to this hypothesis are reports of elevated CSF concentrations of TRH in depressed patients $[57,58]$.

The prolonged release of TRH in depression may be seen as a compensatory response to the decreased 5HT activity in an attempt to normalize 5HT function and maintain normal levels of thyroid hormones [59]. An alternative explanation is that the blunted TSH response may be induced by the hypercortisolism associated with depression or the elevated thyroid hormone levels mediated by adrenergic mechanisms $[60,61]$.

In addition, TRH has been postulated in early studies to have an antidepressant effect.

Administration of TRH at a dose of $500 \mu \mathrm{g}$ parenterally to unipolar depressed women led to a significant improvement in depression ratings [50, 51]. Furthermore, TRH-R1 knockout mice showed increased anxiety and depressionlike behavior thus supporting a role for endogenous TRH in mood regulation [62]. The extent to which the endogenous TRH system is involved in mood regulation and the underlying implicated mechanisms remain to be defined.

\section{Thyroid Hormone Supplementation in Depression}

Thyroid hormones have been used as an adjunct to antidepressant therapy since the late 1960s to accelerate clinical response to antidepressants (acceleration) and to potentiate clinical response in non-responders to antidepressants (augmentation).

An acceleration of antidepressant effect by T3 has been initially shown more than 30 years ago in several reports [6366]. A meta-analysis of these early double-blind placebo controlled trials concluded that T3 was effective in accelerating the clinical response to tricyclic antidepressants in patients with nonrefractory depression. The effects of $\mathrm{T} 3$ acceleration appeared to be more remarkable as the percentage of women in a trial increased therefore suggesting that women might benefit more than men from T3 supplementation [67]. In addition, several reports examined the role of $\mathrm{T} 3$ as an augmentation strategy to antidepressants in refractory depression. The majority involved the use of tricyclic antidepressants and supported the role for T3 in managing refractory depression [68]. More recently, studies assessing the newer and more tolerable antidepressant agents, the selective serotonin reuptake inhibitors (SSRIs) in combination with T3 have yielded confounding results. A meta-analysis of these studies concluded that simultaneous initiation of T3 and SSRI is not significantly more likely to accelerate or enhance the clinical response in depressed patients compared to SSRI monotherapy. However, the authors suggested that T3 and SSRI cotherapy may be effective in a subset of depressed 
patients including those with atypical depression, or those with functional D1 gene polymorphism [69]. As previously described, D1 has a key role in T4 to T3 conversion. In a study by Cooper-Kazaz et al. patients with $\mathrm{C} 785 \mathrm{~T}$ polymorphism in $\mathrm{D} 1$ gene had a better response to $\mathrm{T} 3$ augmentation therapy. Therefore, depressed patients with genetically determined lower T4 to T3 conversion could therefore derive more benefit from thyroid hormone augmentation therapy [70].

Fewer studies assessed the efficacy of T4 in the treatment of affective disorders. Joffe and Singer found a significantly higher response to tricyclic antidepressants with T3 (53\%) compared to T4 (19\%) [71]. However, use of T4 in supraphysiological doses to treatment-resistant unipolar and bipolar depression was effective in approximately $50 \%$ of patients as reported by Baumgartner in a review of eight open clinical trials $(N=78)$ [72]. Surprisingly, T4 in high doses was well tolerated even in patients treated for up to 51 months. However, in healthy subjects, supraphysiological T4 doses were less well tolerated due to higher increments in thyroid hormones after supplementation [73]. A possible explanation would be a greater inactivation of T4 to rT3 in depressed patients compared to healthy subjects [74].

Clearly, further research is needed to ascertain whether thyroid hormone supplementation may effectively accelerate and potentiate therapeutic response to antidepressant drugs. In addition, the role of genetic variations in deiodinase enzymes in the response to antidepressive therapy merits further investigation.

\section{Effect of Depression Treatment on Thyroid Status}

Normalization of pretreatment thyroid function tests mainly T4 levels with remission of depression has been reported $[75,76]$. Whether this is related to clinical recovery or merely a result of a direct effect of antidepressants remains to be determined.

Both tricyclic antidepressants [77] and SSRIs [78] appear to enhance the activity of D2 resulting in an increased conversion of T4 into active T3 in the brain. T3 was suggested to enhance neurotransmission in the central noradrenergic pathways [79] and deficiency in catecholamines has been raised as a possible mechanism in depression [80]. Additionally, it has been shown that anti-depressants with variable mechanisms of action have different effects on thyroid indices [81]. Further studies are therefore required to better elucidate this complex interaction between the HPT axis and the neurotransmitter system.

\section{Association of Depression with Postpartum Thyroid Disease}

The association of postpartum depression with postpartum thyroiditis or with positive thyroid antibodies is still not well defined. Early studies noted a minor association between thyroid dysfunction and postnatal depression [82]. More recently, a higher frequency of mild to moderate depression was observed in postpartum female subjects with positive antithyroid antibodies regardless of thyroid function [8385]. However, an attempt to decrease the incidence of postpartum depression in thyroid antibody positive women with daily administration of thyroxine for 18 weeks postpartum was unsuccessful [86].

\section{Neuroimaging in Thyroid and Mood Disorders}

A few studies have been performed to assess the changes in cerebral perfusion and metabolism in patients with hypothyroidism particularly those with Hashimoto's thyroiditis or status post-thyroidectomy for thyroid carcinoma.

Some have reported diffuse global hypoperfusion [8789] while others demonstrated decreased regional cerebral blood flow [90-92]. Furthermore, variable findings regarding restoration of blood flow with treatment have been documented. While some demonstrated at least partial normalization of cerebral blood flow [14, 87, 89] others found persistent hypoperfusion with restoration of the euthyroid state [90-92].

The inconsistency in the above findings can be accounted for by the variability in the degree of hypothyroidism and the differences in the etiology and duration of the disease in the various studied populations.

Studies assessing cerebral blood flow and metabolism in depression are more numerous. The most widely replicated finding from these studies is hypoperfusion in anterior cortical structures $[93,94]$ that was reversible after psychotherapy and pharmacotherapy [95-97]. In addition to frontal hypoperfusion, increased perfusion has been observed in various limbic regions most notably the amygdala [93].

In a study comparing cerebral blood flow in hypothyroidism and major depression, hypothyroid patients exhibited hypoperfusion in posterior aspects of the brain in contrast to an anterior cerebral hypoperfusion in depressed patients. Furthermore, normalization of perfusion abnormalities in patients with depression after treatment was observed while no change in cerebral blood flow was noted in hypothyroidism. This implies that behavioral symptoms in depression may be mediated by different neural circuits from that seen in hypothyroidism [92].

\section{Conclusion}

Clinical investigators have long recognized the link between thyroid and depression. While patients with hypothyroidism commonly manifest features of depression, hyperthyroidism presents with a wider spectrum of neuropsychiatric symptoms including both depression and anxiety. On the other hand, most of the patients with primary depression have normal thyroid function. The mechanisms underlying the interaction between thyroid function and depression remain to be clarified and a causal relationship between the two cannot be established yet. A possible role for thyroid autoimmunity in the pathogenesis of depression can be elucidated. Screening patients presenting with depression for thyroid dysfunction seems reasonable particularly those with refractory symptoms. However, the use of thyroid hormones as an adjunct 
therapy to antidepressants in the absence of subclinical or clinical hypothyroidism should be further investigated. In addition, specifying a particular patient population that might benefit from this combination as determined by individual genetic variants should be addressed. The continuing research in the biochemical, genetic, and neuroimaging fields seems most promising in providing a deeper understanding of the thyroid-depression interactions.

\section{References}

[1] H. D'haenen, J. A. D. Boer, and P. Willner, Biological Psychiatry, vol. 1, Wiley, Chichester, UK, 2002.

[2] O. M. Wolkowitz and A. J. Rothschild, Psychoneuroendocrinology: The Scientific Basis of Clinical Practice, American Psychiatric, Washington, DC, USA, 1st edition, 2003.

[3] P. R. Larsen, J. E. Silva, and M. M. Kaplan, "Relationships between circulating and intracellular thyroid hormones: physiological and clinical implications," Endocrine Reviews, vol. 2, no. 1, pp. 87-102, 1981.

[4] J. Van Doorn, F. Roelfsema, and D. Van Der Heide, "Concentrations of thyroxine and 3,5,3'-triiodothyronine at 34 different sites in euthyroid rats as determined by an isotopic equilibrium technique," Endocrinology, vol. 117, no. 3, pp. 12011208, 1985.

[5] J. P. Chanoine, S. Alex, S. L. Fang et al., "Role of transthyretin in the transport of thyroxine from the blood to the choroid plexus, the cerebrospinal fluid, and the brain," Endocrinology, vol. 130, no. 2, pp. 933-938, 1992.

[6] J. Robbins and M. Lakshmanan, "The movement of thyroid hormones in the central nervous system," Acta Medica Austriaca, vol. 19, supplement 1, pp. 21-25, 1992.

[7] W. E. Visser, E. C. H. Friesema, J. Jansen, and T. J. Visser, "Thyroid hormone transport in and out of cells," Trends in Endocrinology and Metabolism, vol. 19, no. 2, pp. 50-56, 2008.

[8] G. R. Williams, "Neurodevelopmental and neurophysiological actions of thyroid hormone," Journal of Neuroendocrinology, vol. 20, no. 6, pp. 784-794, 2008.

[9] J. W. Taylor, "Depression in thyrotoxicosis," American Journal of Psychiatry, vol. 132, no. 5, pp. 552-553, 1975.

[10] R. G. Kathol and J. W. Delahunt, "The relationship of anxiety and depression to symptoms of hyperthyroidism using operational criteria," General Hospital Psychiatry, vol. 8, no. 1, pp. 23-28, 1986.

[11] P. T. Trzepacz, M. McCue, I. Klein, G. S. Levey, and J. Greenhouse, "A psychiatric and neuropsychological study of patients with untreated Graves' disease," General Hospital Psychiatry, vol. 10, no. 1, pp. 49-55, 1988.

[12] P. C. Whybrow, A. J. Prange Jr., and C. R. Treadway, "Mental changes accompanying thyroid gland dysfunction. A reappraisal using objective psychological measurement," Archives of General Psychiatry, vol. 20, no. 1, pp. 48-63, 1969.

[13] B. Demartini, A. Masu, S. Scarone, A. E. Pontiroli, and O. Gambini, "Prevalence of depression in patients affected by subclinical hypothyroidism," Panminerva Medica, vol. 52, no. 4, pp. 277-282, 2010.

[14] M. Bauer, D. H. S. Silverman, F. Schlagenhauf et al., "Brain glucose metabolism in hypothyroidism: a positron emission tomography study before and after thyroid hormone replacement therapy," Journal of Clinical Endocrinology and Metabolism, vol. 94, no. 8, pp. 2922-2929, 2009.
[15] R. T. Joffe and A. J. Levitt, "Basal thyrotropin and major depression: relation to clinical variables and treatment outcome," Canadian Journal of Psychiatry, vol. 53, no. 12, pp. 833838, 2008.

[16] P. Saravanan, W. F. Chau, N. Roberts, K. Vedhara, R. Greenwood, and C. M. Dayan, "Psychological well-being in patients on 'adequate' doses of L-thyroxine: results of a large, controlled community-based questionnaire study," Clinical Endocrinology, vol. 57, no. 5, pp. 577-585, 2002.

[17] V. Panicker, P. Saravanan, B. Vaidya et al., "Common variation in the DIO2 gene predicts baseline psychological well-being and response to combination thyroxine plus triiodothyronine therapy in hypothyroid patients," Journal of Clinical Endocrinology and Metabolism, vol. 94, no. 5, pp. 1623-1629, 2009.

[18] W. M. Van Der Deure, B. C. Appelhof, R. P. Peeters et al., "Polymorphisms in the brain-specific thyroid hormone transporter OATP1C1 are associated with fatigue and depression in hypothyroid patients," Clinical Endocrinology, vol. 69, no. 5, pp. 804-811, 2008.

[19] H. J. Baskin, R. H. Cobin, and D. S. Duick, "American association of clinical endocrinologists medical guidelines for clinical practice for the evaluation and treatment of hyperthyroidism and hypothyroidism," Endocrine Practice, vol. 8, no. 6, pp. 457-469, 2002.

[20] R. E. Ingram, The International Encyclopedia of Depression, Springer, New York, NY, USA, 2009.

[21] P. T. Loosen, "Hormones of the hypothalamic-pituitary-thyroid axis: a psychoneuroendocrine perspective," Pharmacopsychiatry, vol. 19, no. 6, pp. 401-415, 1986.

[22] E. Vandoolaeghe, M. Maes, J. Vandevyvere, and H. Neels, "Hypothalamic-pituitary-thyroid-axis function in treatment resistant depression," Journal of Affective Disorders, vol. 43, no. 2, pp. 143-150, 1997.

[23] M. S. Bauer, P. C. Whybrow, and A. Winokur, "Rapid cycling bipolar affective disorder. I. Association with grade I hypothyroidism," Archives of General Psychiatry, vol. 47, no. 5, pp. 427432, 1990.

[24] I. M. D. Jackson, “The thyroid axis and depression," Thyroid, vol. 8, no. 10, pp. 951-956, 1998.

[25] G. M. Sullivan, J. A. Hatterer, J. Herbert et al., "Low levels of transthyretin in the CSF of depressed patients," American Journal of Psychiatry, vol. 156, no. 5, pp. 710-715, 1999.

[26] M. Pilhatsch, C. Winter, K. Nordström, B. Vennström, M. Bauer, and G. Juckel, "Increased depressive behaviour in mice harboring the mutant thyroid hormone receptor alpha 1," Behavioural Brain Research, vol. 214, no. 2, pp. 187-192, 2010.

[27] G. Hennemann, R. Docter, E. C. H. Friesema, M. De Jong, E. P. Krenning, and T. J. Visser, "Plasma membrane transport of thyroid hormones and its role in thyroid hormone metabolism and bioavailability," Endocrine Reviews, vol. 22, no. 4, pp. 451476, 2001.

[28] J. A. Hatterer, J. Herbert, C. Hidaka, S. P. Roose, and J. M. Gorman, "CSF transthyretin in patients with depression," American Journal of Psychiatry, vol. 150, no. 5, pp. 813-815, 1993.

[29] G. M. Sullivan, J. A. Hatterer, J. Herbert et al., "Low levels of transthyretin in the CSF of depressed patients," American Journal of Psychiatry, vol. 156, no. 5, pp. 710-715, 1999.

[30] G. M. Sullivan, J. J. Mann, M. A. Oquendo, E. S. Lo, T. B. Cooper, and J. M. Gorman, "Low cerebrospinal fluid transthyretin levels in depression: correlations with suicidal ideation and low serotonin function," Biological Psychiatry, vol. 60, no. 5, pp. 500-506, 2006. 
[31] T. Suzuki and T. Abe, "Thyroid hormone transporters in the brain," Cerebellum, vol. 7, no. 1, pp. 75-83, 2008.

[32] I. J. Chopra, D. H. Solomon, and T. S. Huang, "Serum thyrotropin in hospitalized psychiatric patients: evidence for hyperthyrotropinemia as measured by an ultrasensitive thyrotropin assay," Metabolism, vol. 39, no. 5, pp. 538-543, 1990.

[33] S. C. Bahls and G. A. De Carvalho, "The relation between thyroid function and depression: a review," Revista Brasileira de Psiquiatria, vol. 26, no. 1, pp. 41-49, 2004.

[34] I. M. D. Jackson and L. G. Luo, "Antidepressants inhibit the glucocorticoid stimulation of thyrotropin releasing hormone expression in cultured hypothalamic neurons," Journal of Investigative Medicine, vol. 46, no. 9, pp. 470-474, 1998.

[35] M. D. Williams, R. Harris, C. M. Dayan, J. Evans, J. Gallacher, and Y. Ben-Shlomo, "Thyroid function and the natural history of depression: findings from the Caerphilly Prospective Study (CaPS) and a meta-analysis," Clinical Endocrinology, vol. 70, no. 3, pp. 484-492, 2009.

[36] B. N. Premachandra, M. A. Kabir, and I. K. Williams, "Low T3 syndrome in psychiatric depression," Journal of Endocrinological Investigation, vol. 29, no. 6, pp. 568-572, 2006.

[37] C. Kirkegaard, A. Korner, and J. Faber, "Increased production of thyroxine and inappropriately elevated serum thyrotropin in levels in endogenous depression," Biological Psychiatry, vol. 27, no. 5, pp. 472-476, 1990.

[38] M. Linnoila, B. A. Lamberg, and W. Z. Potter, "High reverse T3 levels in manic and unipolar depressed women," Psychiatry Research, vol. 6, no. 3, pp. 271-276, 1982.

[39] C. Kirkegaard and J. Faber, "Altered serum levels of thyroxine, triiodothyronines and diiodothyronines in endogenous depression," Acta Endocrinologica, vol. 96, no. 2, pp. 199-207, 1981.

[40] C. B. Nemeroff, "Clinical significance of psychoneuroendocrinology in psychiatry: focus on the thyroid and adrenal," Journal of Clinical Psychiatry, vol. 50, pp. 13-22, 1989.

[41] M. Linnoila, R. Cowdry, and B. A. Lamberg, "CSF triiodothyronine (rT3) levels in patients with affective disorders," Biological Psychiatry, vol. 18, no. 12, pp. 1489-1492, 1983.

[42] C. B. Nemeroff, J. S. Simon, J. J. Haggerty, and D. L. Evans, "Antithyroid antibodies in depressed patients," American Journal of Psychiatry, vol. 142, no. 7, pp. 840-843, 1985.

[43] R. T. Joffe, "Antithyroid antibodies in major depression," Acta Psychiatrica Scandinavica, vol. 76, no. 5, pp. 598-599, 1987.

[44] J. J. Haggerty Jr., D. L. Evans, R. N. Golden, C. A. Pedersen, J. S. Simon, and C. B. Nemeroff, "The presence of antithyroid antibodies in patients with affective and nonaffective psychiatric disorders," Biological Psychiatry, vol. 27, no. 1, pp. 51-60, 1990.

[45] M. S. Gold, A. L. C. Pottash, and I. Extein, "'Symptomless' autoimmune thyroiditis in depression," Psychiatry Research, vol. 6, no. 3, pp. 261-269, 1982.

[46] K. N. Fountoulakis, A. Iacovides, P. Grammaticos, G. S. Kaprinis, and P. Bech, "Thyroid function in clinical subtypes of major depression: an exploratory study," BMC Psychiatry, vol. 4, article 6, 2004.

[47] P. Monteleone, "Circadian rhythm disturbances in depression: implications for treatment and quality of remission," Medicographia, vol. 31, no. 2, pp. 132-139, 2009.

[48] E. Souetre, E. Salvati, T. A. Wehr, D. A. Sack, B. Krebs, and G. Darcourt, "Twenty-four-hour profiles of body temperature and plasma TSH in bipolar patients during depression and during remission and in normal control subjects," American Journal of Psychiatry, vol. 145, no. 9, pp. 1133-1137, 1988.
[49] M. F. Poirier, H. Lôo, A. Galinowskia et al., "Sensitive assay of thyroid stimulating hormone in depressed patients," Psychiatry Research, vol. 57, no. 1, pp. 41-48, 1995.

[50] A. J. Prange Jr., P. P. Lara, I. C. Wilson, L. B. Alltop, and G. R. Breese, "Effects of thyrotropin-releasing hormone in depression," The Lancet, vol. 2, no. 7785, pp. 999-1002, 1972.

[51] A. J. Kastin, R. H. Ehrensing, D. S. Schalch, and M. S. Anderson, "Improvement in mental depression with decreased thyrotropin response after administration of thyrotropin-releasing hormone," The Lancet, vol. 2, no. 7780, pp. 740-742, 1972.

[52] C. B. Nemeroff and D. L. Evans, "Thyrotropin-releasing hormone (TRH), the thyroid axis, and affective disorder," Annals of the New York Academy of Sciences, vol. 553, pp. 304-310, 1989.

[53] P. T. Loosen and A. J. Prange Jr., "Serum thyrotropin response to thyrotropin-releasing hormone in psychiatric patients: a review," American Journal of Psychiatry, vol. 139, no. 4, pp. 405-416, 1982.

[54] C. Kirkegaard, "The thyrotropin response to thyrotropin-releasing hormone in endogenous depression," Psychoneuroendocrinology, vol. 6, no. 3, pp. 189-212, 1981.

[55] P. M. Hinkle and A. H. Tashjian Jr., "Thyrotropin-releasing hormone regulates the number of its own receptors in the GH3 strain of pituitary cells in culture," Biochemistry, vol. 14, no. 17, pp. 3845-3851, 1975.

[56] J. C. Garbutt, J. P. Mayo, K. Y. Little et al., "Dose-response studies with protirelin," Archives of General Psychiatry, vol. 51, no. 11, pp. 875-883, 1994.

[57] C. Kirkegaard, J. Faber, L. Hummer, and P. Rogowski, "Increased levels of TRH in cerebrospinal fluid from patients with endogenous depression," Psychoneuroendocrinology, vol. 4, no. 3, pp. 227-235, 1979.

[58] C. M. Banki, G. Bissette, M. Arato, and C. B. Nemeroff, "Elevation of immunoreactive CSF TRH in depressed patients," American Journal of Psychiatry, vol. 145, no. 12, pp. 1526-1531, 1988.

[59] F. Duval, M. C. Mokrani, P. Bailey et al., "Thyroid axis activity and serotonin function in major depressive episode," Psychoneuroendocrinology, vol. 24, no. 7, pp. 695-712, 1999.

[60] F. Duval, M. C. Mokrani, M. A. Crocq, P. Bailey, and J. P. Macher, "Influence of thyroid hormones on morning and evening TSH response to TRH in major depression," Biological Psychiatry, vol. 35, no. 12, pp. 926-934, 1994.

[61] M. Otsuki, M. Dakoda, and S. Baba, "Influence of glucocorticoids on TRF-induced TSH response in man," Journal of Clinical Endocrinology and Metabolism, vol. 36, no. 1, pp. 95-102, 1973.

[62] H. Zeng, B. A. Schimpf, A. D. Rohde, M. N. Pavlova, A. Gragerov, and J. E. Bergmann, "Thyrotropin-releasing hormone receptor 1-deficient mice display increased depression and anxiety-like behavior," Molecular Endocrinology, vol. 21, no. 11, pp. 2795-2804, 2007.

[63] A. J. Prange Jr., I. C. Wilson, A. M. Rabon, and M. A. Lipton, "Enhancement of imipramine antidepressant activity by thyroid hormone," American Journal of Psychiatry, vol. 126, no. 4, pp. 457-469, 1969.

[64] D. Wheatley, "Potentiation of amitriptyline by thyroid hormone," Archives of General Psychiatry, vol. 26, no. 3, pp. 229233, 1972.

[65] I. C. Wilson, A. J. Prange, T. K. McClane, A. M. Rabon, and M. A. Lipton, "Thyroid-hormone enhancement of imipramine in nonretarded depressions," New England Journal of Medicine, vol. 282, no. 19, pp. 1063-1067, 1970. 
[66] A. Coppen, P. C. Whybrow, R. Noguera, R. Maggs, and A. J. Prange, "The comparative antidepressant value of L-tryptophan and imipramine with and without attempted potentiation by liothyronine," Archives of General Psychiatry, vol. 26, no. 3, pp. 234-241, 1972.

[67] L. L. Altshuler, M. Bauer, M. A. Frye et al., "Does thyroid supplementation accelerate tricyclic antidepressant response? A review and meta-analysis of the literature," American Journal of Psychiatry, vol. 158, no. 10, pp. 1617-1622, 2001.

[68] R. Aronson, H. J. Offman, R. T. Joffe, and C. David Naylor, "Triiodothyronine augmentation in the treatment of refractory depression: a meta-analysis," Archives of General Psychiatry, vol. 53, no. 9, pp. 842-848, 1996.

[69] G. I. Papakostas, R. Cooper-Kazaz, B. C. Appelhof et al., "Simultaneous initiation (coinitiation) of pharmacotherapy with triiodothyronine and a selective serotonin reuptake inhibitor for major depressive disorder: a quantitative synthesis of double-blind studies," International Clinical Psychopharmacology, vol. 24, no. 1, pp. 19-25, 2009.

[70] R. Cooper-Kazaz, W. M. van der Deure, M. Medici et al., "Preliminary evidence that a functional polymorphism in type 1 deiodinase is associated with enhanced potentiation of the antidepressant effect of sertraline by triiodothyronine," Journal of Affective Disorders, vol. 116, no. 1-2, pp. 113-116, 2009.

[71] R. T. Joffe and W. Singer, "A comparison of triiodothyronine and thyroxine in the potentiation of tricyclic antidepressants," Psychiatry Research, vol. 32, no. 3, pp. 241-251, 1990.

[72] A. Baumgartner, "Thyroxine and the treatment of affective disorders: an overview of the results of basic and clinical research," International Journal of Neuropsychopharmacology, vol. 3, no. 2, pp. 149-165, 2000.

[73] M. Bauer, A. Berghöfer, T. Bschor et al., "Supraphysiological doses of L-Thyroxine in the maintenance treatment of prophylaxis-resistant affective disorders," Neuropsychopharmacology, vol. 27, no. 4, pp. 620-628, 2002.

[74] M. Bauer, T. Goetz, T. Glenn, and P. C. Whybrow, "The thyroid-brain interaction in thyroid disorders and mood disorders," Journal of Neuroendocrinology, vol. 20, no. 10, pp. 1101-1114, 2008.

[75] R. T. Joffe and W. Singer, "The effect of tricyclic antidepressants on basal thyroid hormone levels in depressed patients," Pharmacopsychiatry, vol. 23, no. 2, pp. 67-69, 1990.

[76] M. L. Rao, S. Ruhrmann, B. Retey et al., "Low plasma thyroid indices of depressed patients are attenuated by antidepressant drugs and influence treatment outcome," Pharmacopsychiatry, vol. 29, no. 5, pp. 180-186, 1996.

[77] A. Campos-Barros, H. Meinhold, M. Stula et al., "The influence of desipramine on thyroid hormone metabolism in rat brain," Journal of Pharmacology and Experimental Therapeutics, vol. 268, no. 3, pp. 1143-1152, 1994.

[78] A. Baumgartner, M. Dubeyoko, A. Campos-Barros, M. Eravci, and H. Meinhold, "Subchronic administration of fluoxetine to rats affects triiodothyronine production and deiodination in regions of the cortex and in the limbic forebrain," Brain Research, vol. 635, no. 1-2, pp. 68-74, 1994.

[79] P. C. Whybrow and A. J. Prange Jr., "A hypothesis of thyroidcatecholamine-receptor interaction. Its relevance to affective illness," Archives of General Psychiatry, vol. 38, no. 1, pp. 106$113,1981$.

[80] C. A. Kicey, "Catecholamines and depression: a physiological theory of depression," American Journal of Nursing, vol. 74, no. 11, pp. 2018-2020, 1974.
[81] S. S. Eker, C. Akkaya, A. Sarandol, S. Cangur, E. Sarandol, and S. Kirli, "Effects of various antidepressants on serum thyroid hormone levels in patients with major depressive disorder," Progress in Neuro-Psychopharmacology and Biological Psychiatry, vol. 32, no. 4, pp. 955-961, 2008.

[82] B. Harris, H. Fung, S. Johns et al., "Transient post-partum thyroid dysfunction and postnatal depression," Journal of Affective Disorders, vol. 17, no. 3, pp. 243-249, 1989.

[83] V. J. Pop, H. A. de Rooy, H. L. Vader et al., "Postpartum thyroid dysfunction and depression in an unselected population," New England Journal of Medicine, vol. 324, no. 25, pp. 1815-1816, 1991.

[84] B. Harris, S. Othman, J. A. Davies et al., "Association between postpartum thyroid dysfunction and thyroid antibodies and depression," British Medical Journal, vol. 305, no. 6846, pp. 152-156, 1992.

[85] J. L. Kuijpens, H. L. Vader, H. A. Drexhage, W. M. Wiersinga, M. J. Van Son, and V. J. Pop, “Thyroid peroxidase antibodies during gestation are a marker for subsequent depression postpartum," European Journal of Endocrinology, vol. 145, no. 5, pp. 579-584, 2001.

[86] B. Harris, R. Oretti, J. Lazarus et al., "Randomised trial of thyroxine to prevent postnatal depression in thyroid-antibodypositive women," British Journal of Psychiatry, vol. 180, pp. 327-330, 2002.

[87] S. Kinuya, T. Michigishi, N. Tonami, T. Aburano, S. Tsuji, and T. Hashimoto, "Reversible cerebral hypoperfusion observed with Tc-99 m HMPAO SPECT in reversible dementia caused by hypothyroidism," Clinical Nuclear Medicine, vol. 24, no. 9, pp. 666-668, 1999.

[88] E. L. Constant, A. G. De Volder, A. Ivanoiu et al., "Cerebral blood flow and glucose metabolism in hypothyroidism: a positron emission tomography study," Journal of Clinical Endocrinology and Metabolism, vol. 86, no. 8, pp. 3864-3870, 2001.

[89] C. M. Forchetti, G. Katsamakis, and D. C. Garron, "Autoimmune thyroiditis and a rapidly progressive dementia: global hypoperfusion on SPECT scanning suggests a possible mechanism," Neurology, vol. 49, no. 2, pp. 623-626, 1997.

[90] Y. Krausz, N. Freedman, H. Lester et al., "Regional cerebral blood flow in patients with mild hypothyroidism," Journal of Nuclear Medicine, vol. 45, no. 10, pp. 1712-1715, 2004.

[91] S. Nagamachi, S. Jinnouchi, R. Nishii et al., "Cerebral blood flow abnormalities induced by transient hypothyroidism after thyroidectomy: analysis by Tc-99 m-HMPAO and SPM96," Annals of Nuclear Medicine, vol. 18, no. 6, pp. 469-477, 2004.

[92] Y. Krausz, N. Freedman, H. Lester et al., "Brain SPECT study of common ground between hypothyroidism and depression," International Journal of Neuropsychopharmacology, vol. 10, no. 1, pp. 99-106, 2007.

[93] W. C. Drevets, "Neuroimaging studies of mood disorders," Biological Psychiatry, vol. 48, no. 8, pp. 813-829, 2000.

[94] H. S. Mayberg, "Modulating dysfunctional limbic-cortical circuits in depression: towards development of brain-based algorithms for diagnosis and optimised treatment," British Medical Bulletin, vol. 65, pp. 193-207, 2003.

[95] A. L. Brody, S. Saxena, P. Stoessel et al., "Regional brain metabolic changes in patients with major depression treated with either paroxetine or interpersonal therapy: preliminary findings," Archives of General Psychiatry, vol. 58, no. 7, pp. 631640, 2001. 
[96] K. Goldapple, Z. Segal, C. Garson et al., "Modulation of cortical-limbic pathways in major depression: treatment-specific effects of cognitive behavior therapy," Archives of General Psychiatry, vol. 61, no. 1, pp. 34-41, 2004.

[97] S. D. Martin, E. Martin, S. S. Rai, M. A. Richardson, and R. Royall, "Brain blood flow changes in depressed patients treated with interpersonal psychotherapy or venlafaxine hydrochloride: preliminary findings," Archives of General Psychiatry, vol. 58, no. 7, pp. 641-648, 2001. 


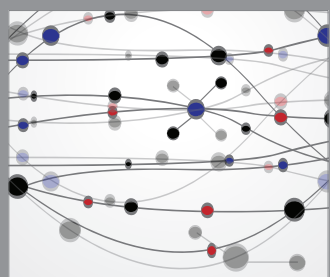

The Scientific World Journal
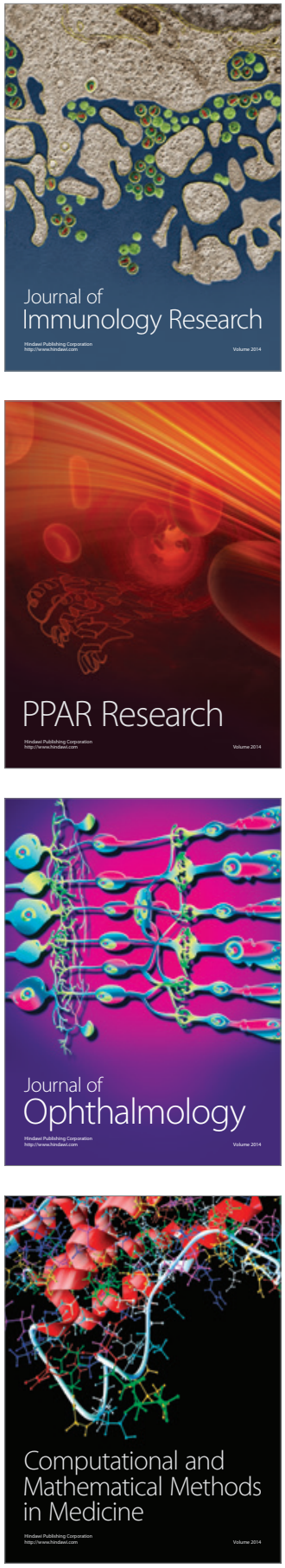

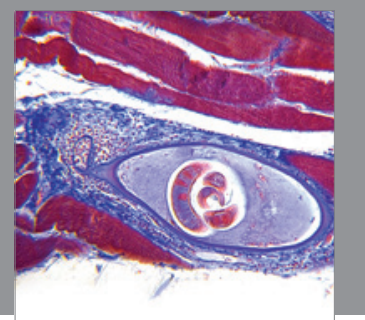

Gastroenterology

Research and Practice
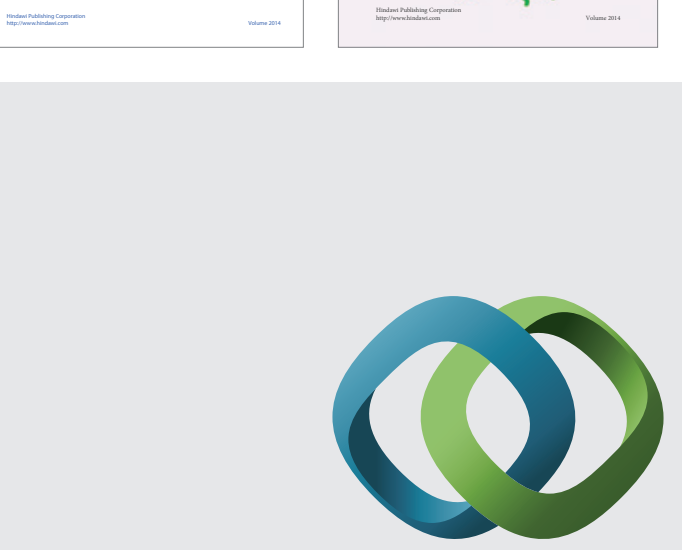

\section{Hindawi}

Submit your manuscripts at

http://www.hindawi.com
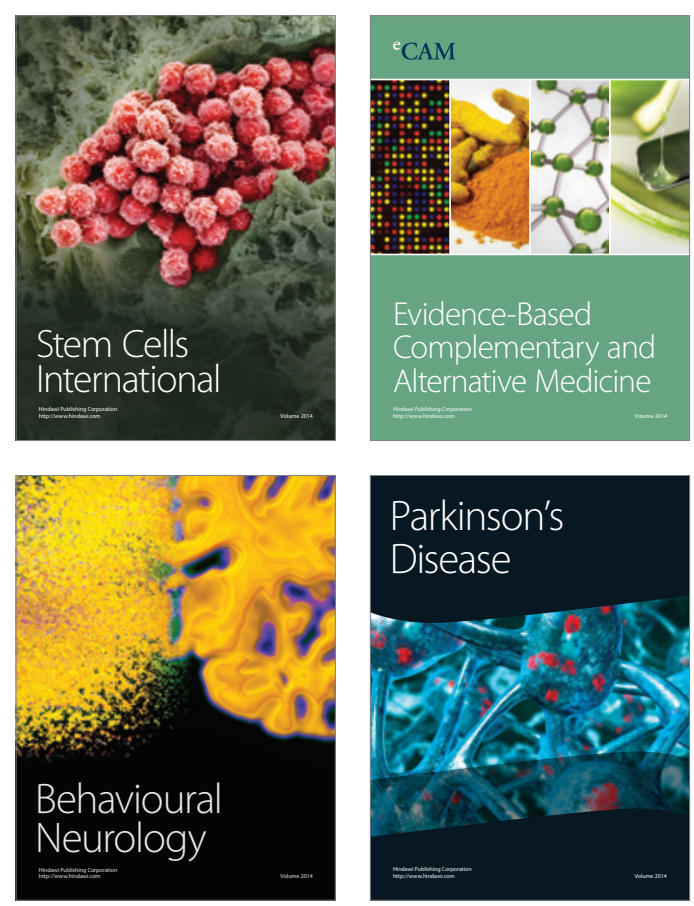

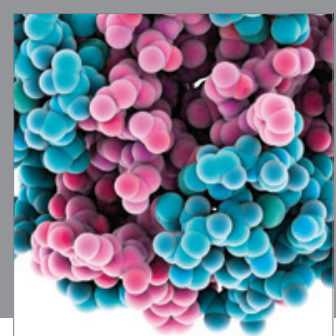

Journal of
Diabetes Research

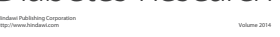

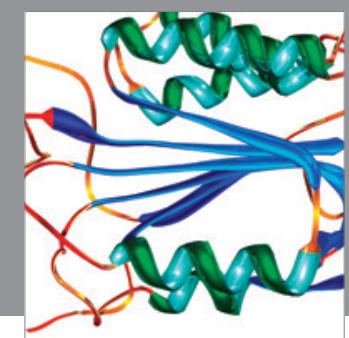

Disease Markers
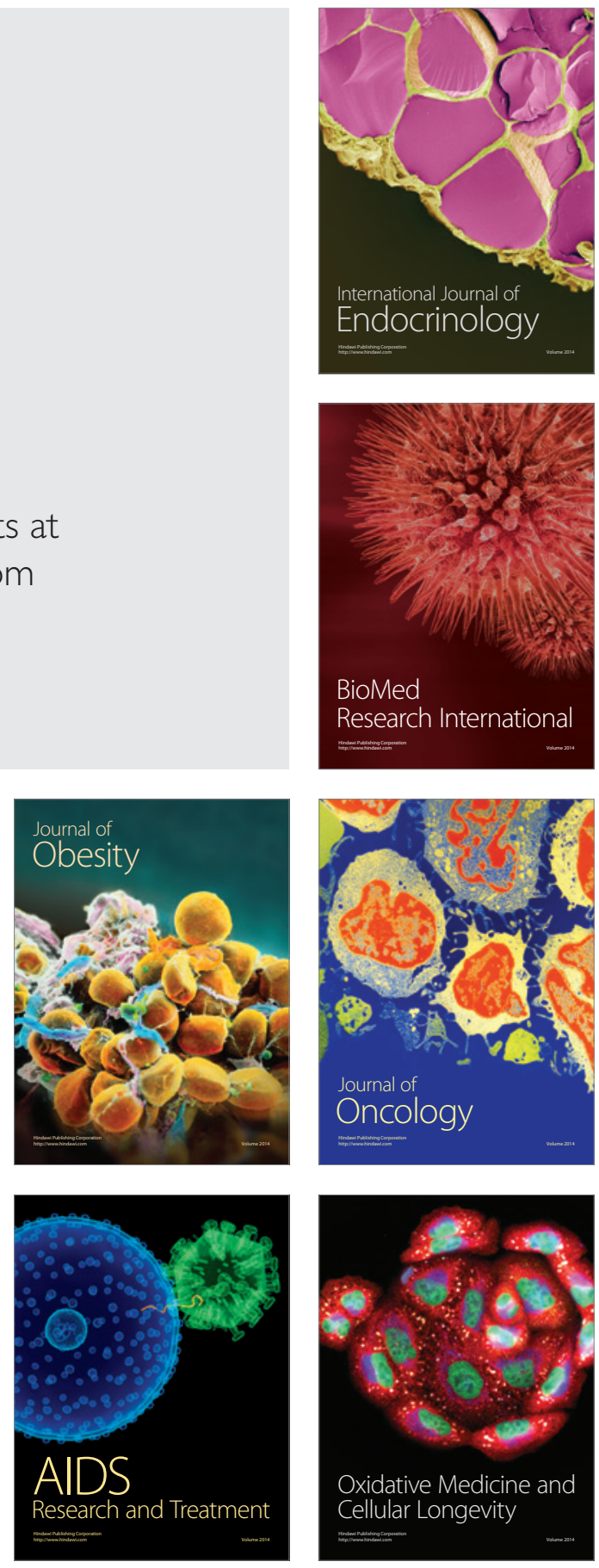